\title{
Assessment of Knowledge, Attitude and Practice of Parents about Immunization in Hail City, 2018
}

\author{
Tamam Murdi Alshammari ${ }^{*}$, Yazeed Saad R Alsubaie ${ }^{2}$, Someili, Suleman Ali ${ }^{3}$, Najla Mohammed \\ Alajmi $^{4}$, Alanazi Khalid Khalaf $\mathbf{M}^{5}$, Mohammed Abdulkareem M Abdrab Alamir ${ }^{6}$, Zayed Ahmad \\ Eisa Albenawi ${ }^{7}$, Ahmed Mohammed Alsahli ${ }^{8}$, Noor Sayed Saleh Darwish Alsharkhat ${ }^{9}$, Abdulaziz \\ Jazza Almejlad $^{10}$, Mohammad Nasser Almatrafi ${ }^{11}$, Almotasem Bllah Ali Alhazmi ${ }^{12}$ \\ ${ }^{1}$ University of Hail, Saudi Arabia, ${ }^{2}$ Majmma University, Saudi Arabia, ${ }^{3}$ Princess Basma Teaching Hospital, Jordan, \\ ${ }^{4}$ Almaarefa University for Science and Technology, Riyadh, Saudi Arabia, ${ }^{5}$ Tabuk University, Saudi Arabia, ${ }^{6}$ Imam \\ Abdulrahman Bin Faisal University, Saudi Arabia,${ }^{7}$ King Khalid University, Abha, Saudi Arabia,${ }^{8}$ General \\ practitioner, University Of Science \&Technology in Sana' a, Yemen, ${ }^{9}$ Jordan University of Science and Technology- \\ Irbid, Jordan, ${ }^{10}$ King Abdulaziz University, Jeddah, Saudi Arabia
}

Corresponding author: Tamam Murdi Alshammari, Email: itamam35@gmail.com

\begin{abstract}
Background: Immunization has shown major preventive aspects of infectious diseases, disability and death. Objectives: Assessing the knowledge, attitude and practice (KAP) of Saudi parents in Hail City regarding the immunization programs for children, Saudi Arabia (KSA), 2018. Methods: It is a cross sectional survey study that was carried out upon 420 parents that were randomly selected as the team focused on collection from public areas to get the appropriate knowledge level from the community for 3 months from May to the end of July, 2018. Parents and were asked to complete a questionnaire. The questionnaire contained 4 different parts about the demographics, knowledge, attitude and practice of parents toward immunization. Results: The included parents have shown a high level of awareness about vaccination regarding the preventive measures and importance of vaccination which resulted in positive attitudes and practice pattern among most of them. The overall KAP was good among most of parents. The higher KAP level wasn't significantly associated with gender, educational degree and number of children. Conclusion: Most of Saudi parents in Hail City had good KAP toward immunization which wasn't associated with gender and educational degrees. However, educational programs are still in need to increase the parents' knowledge and practice especially among illiterate and less educated parents living in rural areas.
\end{abstract}

Keywords: Knowledge, Attitude, Practice (KAP), Immunization, Vaccination, Parents, Children, KSA, 2018.

\section{INTRODUCTION}

Vaccines have thrived as one of the most successful health interventions that have diminished the occurrence of infectious diseases and improved quality of life in the population ${ }^{[1]}$. During the last few decades, the burden of the infectious diseases has been reduced through immunization. It is a safe and effective method of preventing many severe infectious diseases. The most common vaccine-preventable diseases are rubella, measles, diphtheria, tetanus, pertussis, and polio ${ }^{[2,3]}$. The WHO estimated a reduction in the death rate from infectious diseases between 2 and 3 million each year.
Despite the major efforts of health authorities to keep KSA free of diphtheria, pertussis, tetanus, polio, and measles, many physicians face major obstacles from the parents about the safety, efficiency and the necessity of regular childhood vaccines. Giving the child the appropriate vaccine would significantly decrease the costs of disease treatment and rates of disease thus enhance a good quality of life for children ${ }^{[4]}$ .Most of the parents in KSA believed that vaccines can cause autism and disabilities ${ }^{[5]}$. Also, in a global report issued by the CDC, it was stated that the general attitude of parents was negative among most of them toward 
childhood vaccination programs ${ }^{[6]}$. Knowledge and practices among parents regarding immunization are the major factors that contribute to their vaccination decisions ${ }^{[7]}$. Deficiencies in parents' knowledge about the adverse effects and contraindications of vaccines often lead to many immunization errors. Many parents believe there is a relation between mild illness and vaccine contraindication, therefore they considered mild illness as a reason for not giving their children up-to-date vaccinations ${ }^{[8,9]}$. The knowledge, attitude and practice pattern of parents toward vaccination from the first day of birth could provide early prevention from many communicable diseases, disabilities as well as other causes of death ${ }^{[10,11]}$.

\section{AIM OF THE STUDY}

This study aimed at assessing the knowledge, attitude and practice (KAP) of Saudi parents in Hail City regarding the immunization programs for children as well as defining the correlation between KAP and parent's demographics.

\section{METHODS:}

\section{Study design:}

It is a cross sectional survey study that was carried out upon 420 parents that were randomly selected as the team focused on collection from public areas to get the appropriate knowledge level from the community for 3 months from May to the end of July 2018.

\section{Study population:}

The study included 420 different parents having at least one child.

\section{Study tools:}

This survey included an interview with the parents and they were asked to complete a questionnaire. The data of the questionnaire were collected and reviewed by 3 supervisors to test its viability. The questionnaire contained 4 different parts:-

1. Socio-demographics: Age, sex, and educational status.

2. Attitude of parents toward vaccination

3. parents' practice toward immunization of children

\section{Ethical approval}

The study protocol and the questionnaire was approved by the supervisors. The participated parents gave a written informed consent for being involved in the study.

\section{Statistical analysis}

The collected data were analysed using SPSS, version 24 . The descriptive analysis was shown as percentages and frequencies.

\section{RESULTS:}

Demographics of the studied subjects

Table 1. Sociodemographic characteristics of participants

A total of 419 participated in the study, females represented $277(66 \%)$ of the study sample, while males represented 142 (34\%). Parents' age ranges from $<20$ years to $>50$ years and most of them (238) were between $20-29$ years $(56.7 \%)$ and 94 of them were between $30-39$ years $(22.4 \%)$. Most of parents had bachelor degree or more $(79.8 \%), 18.6 \%$ had high school. About $58.6 \%$ of parents have one child, $20.2 \%$ have two or 3 children and only 21.2 had more than 3 children. The demographic details of the sample are summarized in table 1

\section{Table 1. Sociodemographic characteristics of participants}

\begin{tabular}{|ll|}
\hline Variable & $\mathrm{N}(\%)$ \\
\hline Gender & $277(66)$ \\
\hline Female & $142(34)$ \\
\hline Male & \\
\hline Age & $42(10)$ \\
\hline$<\mathbf{2 0}$ & $238(56.7)$ \\
\hline $\mathbf{2 0} \mathbf{- 2 9}$ & $94(22.4)$ \\
\hline $\mathbf{3 0} \mathbf{- 3 9}$ & $36(8.6)$ \\
\hline $\mathbf{4 0}-\mathbf{4 9}$ & $10(2.4)$ \\
\hline $\mathbf{5 0}<$ & \\
\hline Education level & $3(0.7)$ \\
\hline Primary school & $4(1)$ \\
\hline Secondary school & $78(18.6)$ \\
\hline High school & $335(79.8)$ \\
\hline Bachelor or more & \\
\hline Number of children & $246(58.6)$ \\
\hline One & $85(20.2)$ \\
\hline $\mathbf{2 - 3}$ & $89(21.2)$ \\
\hline $\mathbf{3}<$ & \\
\hline
\end{tabular}




\section{Evaluation of the subject's attitude:}

The parent's attitude toward vaccination was positive among most of them as most of them declared

that the vaccination is beneficial and will advise relatives to immunize their children. Also, $83.3 \%$

felt that vaccination is safe and $92.9 \%$ are in favor of obligatory vaccination (Table 3 ).

Table 3. Attitude of parents toward vaccination

Variable

What do you think about vaccination benefits?

\begin{tabular}{|ll|}
\hline Beneficial & $363(86.4)$ \\
\hline Not beneficial & $13(3.1)$ \\
\hline I don't know & $44(10.5)$ \\
\hline $\begin{array}{l}\text { What do you feel when vaccinating your } \\
\text { child? }\end{array}$ \\
\hline Safe & $350(83.3)$ \\
\hline Fear & $70(16.7)$ \\
\hline $\begin{array}{l}\text { Are you in favor of obligatory vaccination } \\
\text { programs designed by the health } \\
\text { authorities? }\end{array}$ \\
\hline Yes & $390(92.9)$ \\
\hline No & $30(7.1)$ \\
\hline $\begin{array}{l}\text { Will you advice your relatives and family } \\
\text { to immunize their children? }\end{array}$ \\
\hline Yes & $396(94.3)$ \\
\hline No & $24(5.7)$ \\
\hline
\end{tabular}

\section{Practice pattern of included parents}

More than half of parents' practice toward vaccination was good among most of them as all of them followed the obligatory vaccination programs. Also, $46.2 \%$ of parents searched for other vaccines. As for pain and swelling management, about $66 \%$ of parents used cold compresses and 59\% used analgesics for pain control (Table 4).

Table 4. Parents' practice toward immunization of children, N $(\%)$

\begin{tabular}{|lll|}
\hline Variable & $\begin{array}{l}\text { Yes } \\
(\%)\end{array}$ & No (\%) \\
\hline $\begin{array}{l}\text { Do you follow the obligatory } \\
\text { vaccination programs? }\end{array}$ & $\begin{array}{l}309 \\
(73.6)\end{array}$ & $111(26.4)$ \\
\hline $\begin{array}{l}\text { Will you search for other available } \\
\text { vaccines for your children? }\end{array}$ & $\begin{array}{l}193 \\
(46)\end{array}$ & $227(54)$ \\
\hline $\begin{array}{l}\text { Will you manage swelling by cold } \\
\text { compress? }\end{array}$ & $\begin{array}{l}277 \\
(66)\end{array}$ & $143(34)$ \\
\hline $\begin{array}{l}\text { Will you use analgesics or swelling and } \\
\text { pain after vaccination? }\end{array}$ & $\begin{array}{l}248 \\
(59)\end{array}$ & $172(41)$ \\
\hline
\end{tabular}

\section{DISCUSSION:}

The childhood immunization programs have played a great part in the prevention of many diseases; hence, vaccination coverage is an indirect way to assess child health care ${ }^{[12]}$. Thus the KAP of parents toward vaccination is important issue to enhance the children health as well as prevention of diseases ${ }^{[13]}$.

Our study revealed that almost all parents were aware of childhood immunization and the majority of them knew the importance of following the immunization schedule to keep their children healthy. Also, most of parents had vaccinated their children according to the $\mathrm{MOH}$ vaccination schedule in Al-Madinah AlMonawara in KSA ${ }^{[14] .}$ The same aspects of high knowledge, attitude and practice were presented in other worldwide studies ${ }^{[15,16]}$. Many studies around the world have shown that successful childhood immunization depends on good knowledge of parents and their positive attitudes [ 17,18,19]. This observation is in contrast with other studies. One of these studies from Libya reported that knowledge of studied mothers about vaccination was not completely adequate ${ }^{[20]}$. In China, Wang et al., observed that $60 \%$ of studied mothers were found to have inadequate knowledge towards immunization in childhood ${ }^{[21]}$. Low levels of knowledge in many countries can be affected by many factors including immunization providers, sources of information and other barriers.

A study from Jeddah City showed a significant association between female gender, high educational degree as well as higher number of children with good KAP results ${ }^{[13]}$. In addition, parents having more children were supposed to have higher KAP results ${ }^{[22,23]}$. Also, study from Al-Mukalla, Yemen showed that parents aged 30 years or younger had significantly lower knowledge scores ${ }^{[24]}$ compared to older parents. This finding is consistent with another study, ${ }^{[25]}$ that reported that older parents have higher knowledge. This may be because older parents are more knowledgeable and experienced.

With regard to attitudes, our findings generally revealed that participants had a positive attitude towards immunization in childhood. All parents 
agreed with vaccination programs and agreed that the vaccination was important. As well, the majority of them agreed that they should follow the vaccination schedule to keep their children healthy. Our finding was consistent with other studies from different countries in which the majority of respondents have a positive attitude towards childhood vaccination [18,24,26,27] "Understanding parents' knowledge and attitudes towards immunization is important" ${ }^{[19]}$. The present study showed some limitations. Most of the parents were from urban areas as it was hard to deal with many rural areas, thus the results can't be generalized to the whole population.

\section{CONCLUSION}

Most of Saudi parents in Hail City had good KAP toward immunization. However, educational programs are still in need to increase the parents' knowledge and practice especially among illiterate and less educated parents living in rural areas.

\section{REFERENCES}

1. Trushitkumar BP, Pathak R, Singh R, Alves V, Mahesh NM, Chaluvaraj TS, Chandramouli R, Varghese B (2017): Assessment of Parents' Knowledge, Attitude and Practice about Child Vaccination in Rural areas. Journal of Pharmaceutical Research, 16 (3): 118764.

2. Yousif MA, Albarraq AA, Abdallah MAA, Elbur AI (2013): Parents' Knowledge and Attitudes on Childhood Immunization, Taif, Saudi Arabia 2013. J Vaccines Vaccin, 5(1): 215- 220.

3. Birhanu S, Anteneh A, Kibie Y, Jejaw A (2015): Knowledge, Attitude and Practice of Mothers Towards Immunization of Infants in Health Centres at Addis Ababa, Ethiopia. American Journal of Health Research, 4(1): 6-17.

4. Siddiqi N, Siddiqi AE, Nisar N, Khan A (2010): Mothers' knowledge about EPI and its relation with ageappropriate vaccination of infants in peri urban Karachi. The Journal of the Pakistan Medical Association ,60(11):940-4.
5. Smith MJ, Woods CR, Marshall GS (2009): Parental vaccine concerns in Kentucky. The Journal of the Kentucky Medical Association, 107(9):342-349.

6. Global Immunization Division Centers for Disease Control and Prevention(2009):Epidemiology of Unimmunized Children: Systematic Review of the Peer-Reviewed Literature.

http://www.who.int/immunization/sage/ 2_Epid_unimm_final_20ct09.pdf

7. Gellin B, Maibach E, Marcuse E(2000): Do parents understand immunizations? A national telephone survey. Pediatrics, 106(5):1097-1102.

8. Richards A, Sheridan J (1999): Reasons for delayed compliance with the childhood vaccination schedule and some failings of computerized vaccination registers. Australian And New Zealand Journal Of Public Health, 23(3):315-7.

9. Schmalz K, Larwa L (1997): Problems encountered by parents and guardians of elementary school-age children in obtaining immunizations. The Journal Of School Nursing, 13(1): 0010310-16.

10. Qutaiba BA-1O, Bahari MB, Al-Qazaz HK, Salih MR, Jamshed SQ, Elkalmi RM (2014): Are parents' knowledge and practice regarding immunization related to pediatrics' immunization compliance? a mixed method study. BMC pediatrics, 14: 20.

11. Bernsen R, Al-Zahmi FR, Al-Ali NA, Hamoudi RO, Ali NA, Schneider J et al. (2011): Knowledge, attitude and practice towards immunizations among mothers in a traditional city in the United Arab Emirates. Hamdan Medical Journal ,4(3): 114-121.

12. Cochran WG (1963): Sampling Techniques .2nd ed. New York: John Wiley and Sons, Inc.

13. Habib R, Alsubhi R, Saadawi D (2018): Assessment of Knowledge, Attitude and Practice of Parents towards Immunization of Children in Saudi 
Arabia. The Egyptian Journal Of Hospital Medicine, 71(2): 2585-2589.

14. Alfahl SO, Alharbi KM (2017): Parents' Knowledge, Attitude and Practice towards Childhood Vaccination, AlMadinah, Saudi Arabia 2017. Journal of Neonatal and Pediatric Medicine, 3(1): 1000126.

15. Joseph J, Devarashetty V, Reddy SN, Sushma M (2015): Parents' knowledge, attitude, and practice on childhood immunization. International Journal of Basic \& Clinical Pharmacology, 4(6) :20151359.

16. Montasser N, Helal R M, Eladawi N, Mostafa E, AbdEl Rahman F, Saad M, Hamza S (2014): Knowledge, Attitude and Beliefs of Caregivers of Children below 2 Years of Age towards Immunization. British Journal of Medicine \& Medical Research, 4(14) :2757-2767.

17. Tang CW, Huang SH, Weng KP, Ger LP (2011): Parents' Views About Vaccination Program in Taiwan. Pediatrics and Neonatology, 52(2): 98102.

18. Angelillo IF1, Ricciardi G, Rossi P, Pantisano P, Langiano E, Pavia M (1999): Mothers and vaccination: knowledge, attitudes, and behavior in Italy. Bull World Health Organ, 77(3): 224-229.

19. Devkot S, Simkhada $P$, Teijlingen $E$ V, Rai L D(2013): Parents' knowledge and practices to childhood immunization in Nepal: implications for health policy. Health Science Journal, 7(4): 370-83.

20. Mabrouka A, Bofarraj M (2011): Knowledge, attitude and practices of mothers regarding immunization of infants and preschool children at AlBeida City, Libya 2008. Egypt J Pediatr Allergy Immunol., 9(1): 29-34.
21. Wang YY, Wang Y, Zhang JX, Kang CY, Duan P(2007): Status of mother's KAP on child immunization in minority areas, Guizhou Province. Beijing Da Xue Xue Bao, 39(2):136-9.

22. Adel Ramadan H, Soliman S M, Abd El-kader R G (2016): Knowledge, Attitude and Practice of Mothers toward Children's Obligatory Vaccination. Journal of Nursing and Health Science, 5(4) 22-28.

23. Mabrouka A.M. Bofarraj (2011): Knowledge, attitude and practices of mothers regarding immunization of infants and preschool children at AlBeida City, Libya 2008. Egypt J Pediatr Allergy Immunol., 9(1):29-34.

24. Al-lela OQ, Bahari MB, Al-Qazaz HK, Salih MR, Jamshed SQ, Elkalmi RM(2014): Are parents' knowledge and practice regarding immunization related to pediatrics' immunization compliance? a mixed method study. BMC Pediatr., 14(20) 1471-2431.

25. Yousif M, Albarraq A, Abdallah M, Elbur A (2013): Parents' knowledge and attitudes on childhood immunization, Taif, Saudi Arabia. Journal of Vaccines and Vaccination, 5(215) 2157-7560.

26. Zagminas K, Surkiene G, Urbanovic N, Stukas R (2007): Parental attitudes toward children's vaccination. Medicina (Kaunas), 43(2):161-9.

27. Al-Zahrani JO (2013): knowledge, attitudes and practices of parents towards childhood vaccination MAJMAAH J. Health Sciences, 1(1):30-8. 